\title{
Hemodynamic impacts of flow diverter devices on the ophthalmic artery
}

\author{
Xinzhi Wu, Zhongbin Tian, Jian Liu, Wenqiang Li, Junfan Chen, Yangyang Zhou, Xinjian Yang and Shiqing Mu* (D)
}

\begin{abstract}
Background: Flow diverter devices are increasingly used for endovascular treatment of internal carotid artery aneurysms. Treatment of ophthalmic segment aneurysms with flow diverter devices also includes coverage of the ophthalmic artery but may result in complications. It is unclear, however, whether these devices mechanically block blood flow in the ophthalmic artery. Also unclear is the relationship between deployment of a flow diverter device and posttreatment occlusion. We studied hemodynamic changes in the ophthalmic artery after deployment of a flow diverter device to determine the relationship between those changes and post-stent occlusion of the artery.

Methods: We analyzed hemodynamic modifications in the ophthalmic artery in 21 patients (19 women, 2 men; mean age $53.43 \pm 7.32$ years) treated by a single pipeline embolization device. Patient-specific geometries were determined from three-dimensional digital subtraction angiography and the stenting process was simulated. Computational fluid dynamics technology was used to analyze the change in ophthalmic artery hemodynamics. We compared pre-treatment and post-treatment flow velocity of the ophthalmic artery.

Results: Among the 21 patients with aneurysms located in the ophthalmic segment, no ophthalmic artery occlusion was found during immediate or follow-up angiography. Post-stent flow velocity in the ophthalmic artery decreased from $0.35 \pm 0.19$ to $0.33 \pm 0.20 \mathrm{~m} / \mathrm{s}$, with the difference not being statistically significant $(P=0.106)$.

Conclusion: Our results showed no significant change in ophthalmic artery blood flow after pipeline embolization device deployment. Hence, post-stent occlusion of the ophthalmic artery could not be explained by reduced blood flow. Delayed thrombosis and neointimal formation maybe the keys to ophthalmic artery occlusion and need further investigation.
\end{abstract}

Keywords: Ophthalmic artery, Aneurysm, Flow diverter device, Computational fluid dynamics

\section{Background}

Flow diverter devices have been recognized as important tools to treat intracranial aneurysms [1,2]. The pipeline embolization device (PED, eV3/Covidien, Irvine, CA) is a flow diverter device approved for use in the treatment of large or giant wide-necked intracranial aneurysms arising from the internal carotid artery between the petrous and hypophyseal segments. Major branches of the internal carotid artery, especially the ophthalmic artery, were often covered by the PED during treatment of ophthalmic

\footnotetext{
*Correspondence: mu_sq1216@163.com
}

Department of Interventional Neuroradiology, Beijing Neurosurgical

Institute, Beijing Tiantan Hospital, Capital Medical University,

Beijing 100070, China segment aneurysms. After PED deployment, aneurysmal flow exhibits reduced fluid dynamic activity [3]. Aneurysms treated with the PED have a high rate of complete occlusion. A recent study reported $86.8 \%$ occlusion at 1-year follow-up, which increased to $93.4 \%$ and $95.2 \%$ at 3 - and 5-year follow-ups, respectively $[4,5]$.

Because the ophthalmic artery can be covered following PED treatment of aneurysms, the patency of the ophthalmic artery is a major concern, as are the clinical results. There are several reports in the literature of ophthalmic artery occlusion and correlated symptoms after PED deployment. Mascitelli et al. [6] described a patient whose ophthalmic artery was covered by PED and occluded immediately. Rouchaud et al. [7] reported that $39.3 \%$ patients in their study developed new ophthalmic

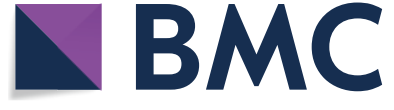

(c) The Author(s) 2019. This article is distributed under the terms of the Creative Commons Attribution 4.0 International License (http://creativecommons.org/licenses/by/4.0/), which permits unrestricted use, distribution, and reproduction in any medium, provided you give appropriate credit to the original author(s) and the source, provide a link to the Creative Commons license, and indicate if changes were made. The Creative Commons Public Domain Dedication waiver (http://creativecommons.org/ publicdomain/zero/1.0/) applies to the data made available in this article, unless otherwise stated. 
complications. Limited previous studies have shown that the immediate and delayed occlusion rates of covered ophthalmic arteries range from 5.9 to $21.0 \%$ [8-11], but the mechanism of the occlusion was still uncertain, and the post-treatment hemodynamic modification of the ophthalmic artery was unknown.

Aneurysms covered by a PED have a high rate of occlusion, which could be correlated with reduced flow velocity [12]. It is possible that the ophthalmic artery covered by a PED also has reduced flow velocity and other hemodynamic indices related to its post-procedure occlusion. Computational fluid dynamics (CFD) technology is a valid method for evaluating cerebral vascular hemodynamics [13]. In this study, we aimed to identify the hemodynamic changes in the ophthalmic artery induced by PED and the relationship between those changes and the occlusion of the ophthalmic artery.

\section{Methods}

\section{Study population}

From November 2015 to May 2018, 21 subjects with aneurysms were recruited and enrolled in our study. The aneurysms met the following criteria: (1) treated by a single PED with coverage of the ophthalmic artery; (2) unruptured intracranial aneurysm; (3) reconstructed three-dimensional model of the ipsilateral internal carotid artery was available; (4) the landing zone of the PED could be identified by digital subtraction angiography images. Exclusion criteria included a ruptured aneurysm, dissection aneurysm and traumatic aneurysm. The ethics board of our hospital approved the study and all patients agreed to participate and signed informed consent forms. The average age of recruited patients was $53.43 \pm 7.32$ years. The mean age for women $(n=19)$ was $53.0 \pm 7.16$ years and for men $(n=2) 57.5 \pm 10.61$ years. The mean follow-up time was $6.45 \pm 2.83$ months. Patient demographics, aneurysm characteristics and treatment strategies displayed in Table 1.

\section{Vessels and stent deployment modeling}

The three-dimensional vessel geometries were reconstructed from Digital subtraction angiography images. The images were segmented and smoothed using Geomagic Studio (version 12.0; Geomagic, Research Triangle Park, NC), and the surface geometries were saved as standard tessellation language (STL) format files. The process included three main procedures: (1) pre-processing using vessel-specific initialization to isolate the parent vessel and create simplex mesh that fit the vessel by its centerline; (2) expanding the simplex mesh to make the deployed simplex mesh closely join the wall of the parent vessel; (3) post-processing. The deployed stent was merged with the aneurysm geometry using ICEM
Table 1 Patient demographics, aneurysm characteristics and treatment strategies of the patients with coverage of ophthalmic artery after PED deployment

\begin{tabular}{ll}
\hline Characteristic & Value \\
\hline No. of patients & 21 \\
Average age (years) & \\
Male & $57.5 \pm 10.61$ \\
Female & $53.0 \pm 7.16$ \\
Sex & \\
Male & 2 \\
Female & 19 \\
Mean aneurysm size (mm) & $8.3 \pm 4.8$ \\
Mean ophthalmic artery diameter (mm) & $1.1 \pm 0.18$ \\
Treatment strategy & \\
PED & $16(76.2 \%)$ \\
PED + coil & $5(23.8 \%)$ \\
Mean follow-up time (months) & $6.4 \pm 2.8$ \\
\hline
\end{tabular}

CFD version 14.0 (ANSYS, Inc., Canonsburg, PA). Figure 1 displays a representative case of the reconstructed vascular model and the virtually implanted PED.

\section{CFD modeling}

The CFD simulations were as described previously [14, 15], with each aneurysm model imported into the automatic mesh generation software ICEM CFD to create finite-volume element grids for CFD simulations. The maximum element size was set at $0.2 \mathrm{~mm}$. To present the geometry of the pipeline stent sufficiently, the element size on the stent was set at $0.01 \mathrm{~mm}$ (approximately onethird the width of the strut of the pipeline stent [16]). A high resolution advection scheme was used in our CFD modeling. Time steps were set at $0.001 \mathrm{~s}$. The untreated cases comprised 1 million tetrahedral elements and the cases treated by PED comprised 5 million tetrahedral elements. To ensure the accuracy of solved flow near walls, we applied three layers of prismatic grid in a hybrid grid near the wall, and applied a tetrahedron grid in the other field. The ANSYS CFX 14.0 was then used to solve the flow-governing Navier-Stokes equations. The blood vessel walls were supposed to be rigid, with no-slip boundary conditions. The blood flow was assumed to have laminar flow (Additional file 1: Table S1) and be a homogeneous, incompressible Newtonian fluid. The dynamic viscosity of the blood flow was set at $0.004 \mathrm{~kg} / \mathrm{m} / \mathrm{s}$ and the density of blood at $1060 \mathrm{~kg} / \mathrm{m}^{3}$. Using transcranial Doppler imaging, we obtained a representative pulsatile period velocity profile from a normal human, which we used to set the inflow boundary conditions. The pressure distribution along the parent artery, the ophthalmic artery and in the aneurysm were then computed using 


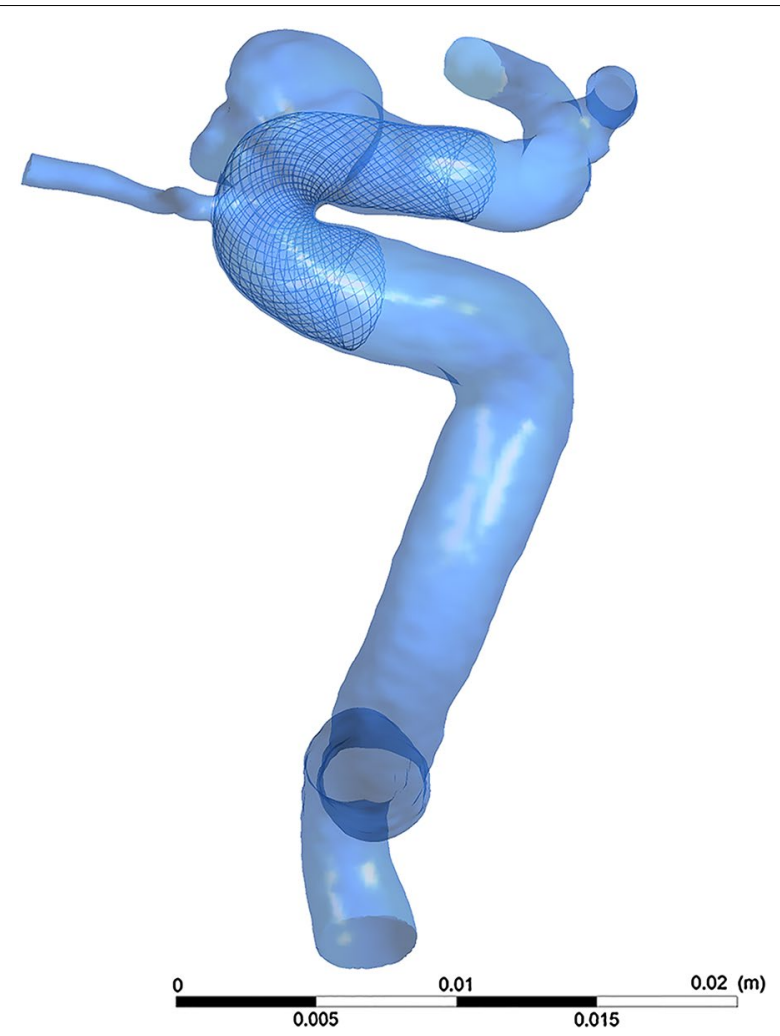

Fig. 1 A representative case of the reconstructed vascular model and the virtually implanted PED

the drop in pressure calculated during the CFD simulations with respect to $\mathrm{P}=10,000 \mathrm{~Pa}$ prescribed at the outlet $[17,18]$. Flow waveforms were scaled to achieve a mean inlet wall shear stress (WSS) of 1.5 Pa under pulsatile conditions [18]. Traction-free boundary conditions were implemented at the outlet. To avoid initial transient variation, two complete cardiac cycles were computed, and data of the second cycle were gathered.

\section{Velocity measurement}

The flow velocity in the ophthalmic artery was measured at a transection of its ostium at peak systole. Enlargement of the ophthalmic artery's origin was avoided during the process of obtaining the cut plane. The flow velocity in aneurysms was defined as the average velocity of the entire aneurysm at peak systole.

\section{Statistical analysis}

Statistical analysis was performed with SPSS Statistics for Windows, Version 17.0 (SPSS Inc., Chicago, IL). All quantitative hemodynamic parameters (before and after stent implantation) were summarized as the mean \pm SD if normally distributed, and then analyzed with the pairedsamples $t$ test. A P value $<0.05$ was considered statistically significant.

\section{Results}

The hemodynamic results before and after PED deployment in our patients are shown in Table 2. Eighteen of the 21 treated aneurysms (85.7\%) were demonstrated complete occlusion at follow-up. All the 21 (100\%) ophthalmic arteries covered by PED were still patent according to angiography performed immediately and at a later follow-up. Two (9.5\%) of 21 patients experienced visual symptoms in spite of patency of the ophthalmic artery.

The pre- and post-procedural flow velocity of the ophthalmic artery and intra-aneurysmal flow are shown in Fig. 2. Before deployment of the pipeline stent, the blood flow velocity in the ophthalmic artery was $0.35 \pm 0.19 \mathrm{~m} / \mathrm{s}$. The post-procedural flow velocity was $0.33 \pm 0.20 \mathrm{~m} / \mathrm{s} \quad(\mathrm{P}=0.106)$. The velocity in the aneurysm significantly decreased, dropping from $0.10 \pm 0.09$ to $0.05 \pm 0.07 \mathrm{~m} / \mathrm{s}(\mathrm{P}<0.001)$. The flow reduction ratio [(pre-treatment parameter - post-treatment parameter)/ pre-treatment parameter] of the ophthalmic artery was $6.13 \pm 10.37 \%$. The flow reduction ratio of the aneurysm was $62.36 \pm 25.75 \%$. Figure 3 depicts the mean flow velocity reduction ratio in ophthalmic artery versus aneurysm and sex differences.

\section{Discussion}

This study of hemodynamic changes from before deployment of the flow diverter device to afterward showed that flow velocity changes in the ophthalmic artery at peak systole were not significant. The blocking effect of the PED on ophthalmic artery blood flow was limited compared with its blocking effect on the intra-aneurysmal flow velocity. This result is opposite from what we expectedthat the metal stent would likely block the blood flow into the ophthalmic artery. We have, for the first time, shown that blood flow in the ophthalmic artery covered by a PED is not reduced as much as it is in the aneurysm, remaining the same as it was before the stent was deployed.

$\mathrm{Hu}$ et al. [19] studied blood flow reduction in 31 patients with covered anterior inferior cerebellar arteries using the CFD approach. The group modeled deployment of the flow diverter device into the basilar artery and covered the anterior inferior cerebellar arteries. Flow velocity reduction of each anterior inferior cerebellar artery after deployment of flow diverter device was measured. They reported that blood flow reduction in the anterior inferior cerebellar artery was $3.6175 \pm 1.94 \%$ and concluded that there was no significant change in the blood 
Table 2 Summary of the clinical characteristics and hemodynamic results before and after PED deployment in our 21 patients

\begin{tabular}{|c|c|c|c|c|c|c|c|c|c|}
\hline \multirow[t]{2}{*}{ Case no. } & \multirow[t]{2}{*}{ Sex, age (year) } & \multirow[t]{2}{*}{ Aneurysm site } & \multirow[t]{2}{*}{$\begin{array}{l}\text { Aneurysm } \\
\text { size }(\mathrm{mm})\end{array}$} & \multicolumn{2}{|c|}{$\begin{array}{l}\text { Pre-treatment velocity } \\
\left(\mathrm{m} \mathrm{s}^{-1}\right)\end{array}$} & \multicolumn{2}{|c|}{$\begin{array}{l}\text { Post-treatment velocity } \\
\left(\mathrm{m} \mathrm{s}^{-1}\right)\end{array}$} & \multicolumn{2}{|c|}{ Reduction ratio (\%) } \\
\hline & & & & OphA & Aneurysm & OphA & Aneurysm & OphA & Aneurysm \\
\hline 1 & $M, 50$ & lc6 & 5.41 & 0.12 & 0.02 & 0.10 & 0.00 & 16.52 & 80.33 \\
\hline 2 & $F, 43$ & Ic6 & 4.64 & 0.19 & 0.05 & 0.15 & 0.02 & 19.86 & 63.46 \\
\hline 3 & $F, 58$ & lc5 & 0.96 & 0.12 & 0.04 & 0.08 & 0.01 & 32.83 & 85.72 \\
\hline 4 & $F, 62$ & lc6 & 3.31 & 0.66 & 0.36 & 0.77 & 0.30 & -17.63 & 16.96 \\
\hline 5 & $F, 52$ & rc6 & 4.31 & 0.09 & 0.02 & 0.08 & 0.00 & 11.75 & 79.89 \\
\hline 6 & $F, 42$ & rc6 & 5.77 & 0.34 & 0.11 & 0.32 & 0.04 & 7.23 & 67.47 \\
\hline 7 & $F, 53$ & rc6 & 3.8 & 0.38 & 0.22 & 0.34 & 0.06 & 11.09 & 71.91 \\
\hline 8 & $F, 52$ & Ic6 & 3.15 & 0.43 & 0.16 & 0.38 & 0.06 & 11.77 & 64.12 \\
\hline 9 & $F, 48$ & lc6 & 5.32 & 0.35 & 0.12 & 0.38 & 0.04 & -7.51 & 63.41 \\
\hline 10 & $F, 43$ & lc6 & 2.24 & 0.08 & 0.03 & 0.07 & 0.00 & 5.96 & 87.85 \\
\hline 11 & $M, 65$ & rc6 & 5.5 & 0.50 & 0.08 & 0.48 & 0.03 & 3.75 & 64.55 \\
\hline 12 & $F, 53$ & rc6 & 4.43 & 0.40 & 0.20 & 0.38 & 0.12 & 6.13 & 42.62 \\
\hline 13 & $F, 57$ & Ic6 & 5.55 & 0.36 & 0.09 & 0.31 & 0.03 & 12.67 & 64.28 \\
\hline 14 & $F, 62$ & lc6 & 8.57 & 0.49 & 0.18 & 0.47 & 0.10 & 4.30 & 45.24 \\
\hline 15 & $F, 57$ & Ic5 & 19.8 & 0.79 & 0.03 & 0.75 & 0.00 & 4.98 & 85.47 \\
\hline 16 & $F, 46$ & rc6 & 4.31 & 0.35 & 0.23 & 0.34 & 0.08 & 2.86 & 63.83 \\
\hline 17 & $F, 58$ & rc6 & 4.64 & 0.44 & 0.01 & 0.45 & 0.00 & -0.34 & 90.88 \\
\hline 18 & $F, 53$ & rc6 & 6.09 & 0.16 & 0.05 & 0.16 & 0.02 & -3.66 & 65.01 \\
\hline 19 & $F, 63$ & Ic5 & 13.8 & 0.54 & 0.07 & 0.51 & 0.02 & 5.36 & 75.49 \\
\hline 20 & $F, 62$ & rc5 & 4.95 & 0.28 & 0.06 & 0.27 & 0.03 & 4.48 & 51.91 \\
\hline 21 & $F, 43$ & rc6 & 21.1 & 0.16 & 0.01 & 0.17 & 0.01 & -3.76 & -20.83 \\
\hline
\end{tabular}

flow in the anterior inferior cerebellar arteries due to PED treatment, similar to the results of our study.

Ouard et al. [12] studied the relationship between post-stent blood flow reduction and complete occlusion of aneurysms by means of CFD analysis. Hemodynamic characteristics of intra-aneurysmal flow with and without a virtual stent were compared. They concluded that to achieve complete occlusion of the aneurysm, blood flow velocity in sidewall aneurysms must be reduced at least one-third from pre-stent velocities. There may also be a minimum blood flow reduction threshold for post-stent ophthalmic arteries. In our study, the blood flow reduction after deployment of a single pipeline stent apparently did not reach this minimum threshold. This hypothesis should be confirmed in a subsequent study.

In our prior research, Wang et al. [20] studied $10 \mathrm{~min}$ iature pigs to investigate the flow obstruction effect of the PED, Low-profile Visualized Intraluminal Support (LVIS) and Solitaire stents on blood flow in collateral arteries. Stents were inserted into an internal carotid artery segment of miniature pigs that covered at least one collateral branch. Angiography was performed immediately after stent deployment and obstruction of blood flow to brain were evaluated by magnetic resonance imaging. Stents were examined to find evidence of neointima formation. No obstruction was found in the collateral branches and neointima formation were observed in the stents. Dai et al. [21] conducted an in vivo study to investigate patency of branches after coverage with multiple telescoping PEDs. Rabbits were divided into 3 groups (single, double and triple PED). Follow-ups were conducted at 6 and 12 months. All the covered branches were patent at follow-up. However, partial neointimal coverage of ostia of the branches was seen. As the neointima was not continuous, investigators observed prompt flow into the branches from the aorta during a saline flush. We speculate that the ostia of the branches would be completely covered by neointima with a longer duration follow-up. Kulcsar et al. [22] postulated that neointimal hyperplasia was a possible explanation for delayed infarctions in their 3 patients. The theories above can explain why some ophthalmic arteries became occluded without flow velocity changes soon after PED deployment.

The reports in the literature for post-treatment occlusion rate of ophthalmic arteries ranging from 5.9 to $21.0 \%$ [8-11] were perplexing because we found no ophthalmic artery occlusion. We think the difference is because of the enrollment process. In order to eliminate 


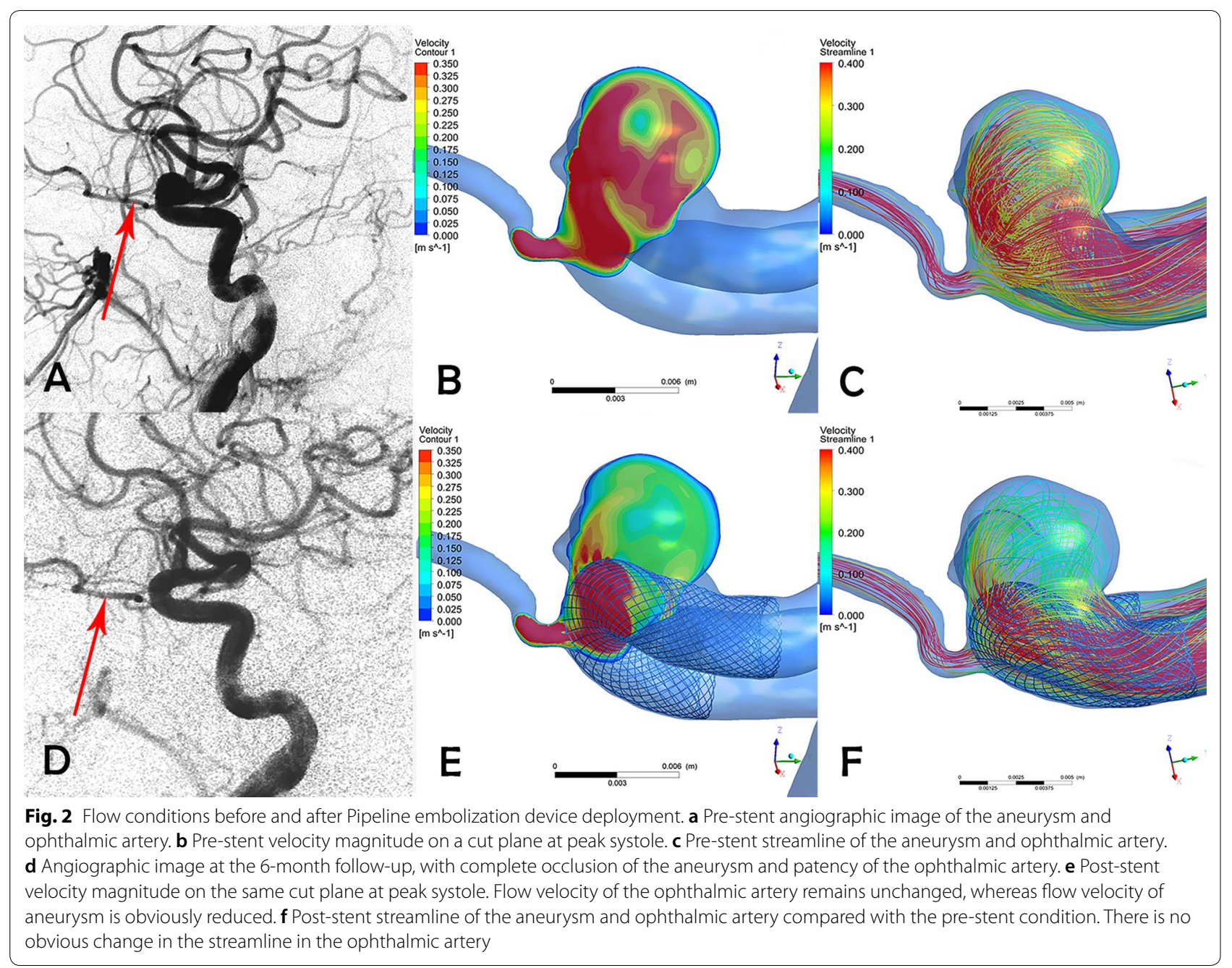

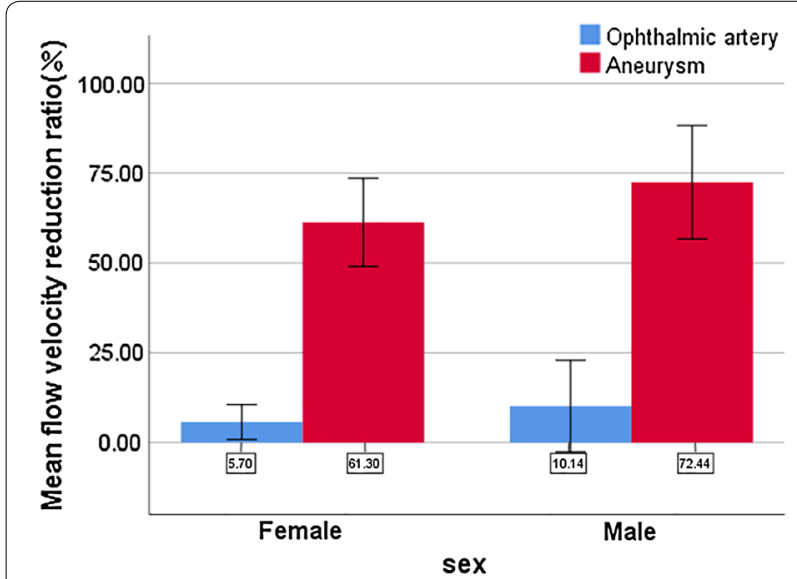

Fig. 3 Mean flow velocity reduction ratio in ophthalmic artery versus aneurysm and sex differences the influence of a coil on the accuracy of the results, we enrolled stent-only cases and specifically those with an ophthalmic artery originating from a parent artery. Perhaps there is less post-treatment flow reduction in the ophthalmic artery without coils. Further study of this issue is warranted.

The present study confirms that there is no significant change in ophthalmic artery blood flow. However, this study has several limitations. First, only 21 patients with ophthalmic artery covered were recruited in our study. This limited number of subjects may affect the accuracy of our results. Second, blood vessels walls were assumed to be rigid, which might not represent the true physiology of the human body. Third, no patients with occluded ophthalmic arteries were enrolled in our study, and more persuasive results might have been obtained with such cases. Finally, blood is modeled as a Newtonian fluid with laminar flow, which may affect the hemodynamic results. 


\section{Conclusion}

This is the first study analyzing blood flow changes in the ophthalmic artery using CFD technology. We found that PEDs exerted little to no influence on blood flow in the ophthalmic artery; at the very least, the influence was not as great as believed. It is likely that hemodynamic changes such as blood flow reduction are not responsible for the occlusion and other complications of the ophthalmic artery after pipeline stent deployment. Formation of neointima maybe responsible for this occlusion and requires more indepth investigation (Additional file 1: Table S1).

\section{Additional file}

Additional file 1: Table S1. Reynolds value and proves this assumption.

\section{Abbreviations}

CFD: computational fluid dynamics; PED: pipeline embolization device.

\section{Acknowledgements}

We thank Nancy Schatken BS, MT (ASCP) and Sara Connell, OD, from Liwen Bianji, Edanz Group China (http://www.liwenbianji.cn/ac), for editing the English text of drafts of this manuscript.

\section{Authors' contributions}

XW collected the clinical data, performed CFD analysis and wrote manuscript writing. ZT and WL participated in the process of CFD modeling. $J L$ and XY helped revise the manuscript. JC and YZ helped with statistics collecting. SM conceived of and designed the research and handled funding and supervision. All authors read and approved the final manuscript.

\section{Funding}

This work was supported by the National Key Research and Development Plan of China (Grant Number: 2016YFC1300800), the National Natural Science Foundation of China (Grant Numbers: 81220108007, 81371315, 81801156, 81801158,81471167 and 81671139) and the Special Research Project for Capital Health Development (Grant Number: 2018-4-1077).

\section{Availability of data and materials}

All clinical data related to this study are stored by an information system at the Department of Interventional Neuroradiology, Beijing Neurosurgical Institute and Beijing Tian Tan Hospital, Capital Medical University.

\section{Ethics approval and consent to participate}

The research was permitted by the ethics committee of Beijing Tian Tan Hospital and written informed consents was obtained from all patients.

\section{Consent for publication}

Not applicable.

\section{Competing interests}

The authors declare that they have no competing interests.

Received: 12 November 2018 Accepted: 8 May 2019

Published online: 16 May 2019

\section{References}

1. Brinjikji W, Murad MH, Lanzino G, Cloft HJ, Kallmes DF. Endovascular treatment of intracranial aneurysms with flow diverters: a meta-analysis. Stroke. 2013;44:442-7.
2. Kan P, Siddiqui AH, Veznedaroglu E, Liebman KM, Binning MJ, Dumont TM, Ogilvy CS, Gaughen JR Jr, Mocco J, Velat GJ, et al. Early postmarket results after treatment of intracranial aneurysms with the pipeline embolization device: a U.S. multicenter experience. Neurosurgery. 2012;71:1080-7 (discussion 1087-1088).

3. Roszelle BN, Gonzalez LF, Babiker MH, Ryan J, Albuquerque FC, Frakes $\mathrm{DH}$. Flow diverter effect on cerebral aneurysm hemodynamics: an in vitro comparison of telescoping stents and the pipeline. Neuroradiology. 2013;55:751-8.

4. Becske T, Brinjikji W, Potts MB, Kallmes DF, Shapiro M, Moran CJ, Levy El, McDougall CG, Szikora I, Lanzino G, et al. Long-term clinical and angiographic outcomes following pipeline embolization device treatment of complex internal carotid artery aneurysms: five-year results of the pipeline for uncoilable or failed aneurysms trial. Neurosurgery. 2017;80:40-8.

5. Becske T, Potts MB, Shapiro M, Kallmes DF, Brinjikji W, Saatci I, McDougall CG, Szikora I, Lanzino G, Moran CJ, et al. Pipeline for uncoilable or failed aneurysms: 3-year follow-up results. J Neurosurg. 2017;127:81-8

6. Mascitelli JR, Pain M, Panov F, Bederson JB, Patel AB. Ophthalmic artery occlusion immediately following placement of a flow diverter without clinical sequelae. Interv Neuroradiol. 2015;21:191-5.

7. Rouchaud A, Leclerc O, Benayoun Y, Saleme S, Camilleri Y, D'Argento F, Boncoeur MP, Robert PY, Mounayer C. Visual outcomes with flowdiverter stents covering the ophthalmic artery for treatment of internal carotid artery aneurysms. AJNR Am J Neuroradiol. 2015;36:330-6.

8. Gascou G, Lobotesis K, Brunel H, Machi P, Riquelme C, Eker O, Bonafe A, Costalat V. Extra-aneurysmal flow modification following pipeline embolization device implantation: focus on regional branches, perforators, and the parent vessel. AJNR Am J Neuroradiol. 2015:36:725-31.

9. Puffer RC, Kallmes DF, Cloft HJ, Lanzino G. Patency of the ophthalmic artery after flow diversion treatment of paraclinoid aneurysms. J Neurosurg. 2012;116:892-6.

10. Rangel-Castilla L, Munich SA, Jaleel N, Cress MC, Krishna C, Sonig A, Snyder KV, Siddiqui AH, Levy El. Patency of anterior circulation branch vessels after pipeline embolization: longer-term results from 82 aneurysm cases. J Neurosurg. 2017;126:1064-9.

11. Cagnazzo F, Lefevre PH, Mantilla D, Rouchaud A, Morganti R, Perrini P, Carlo DD, Dargazanli C, Gascou G, Riquelme C, et al. Patency of the supraclinoid internal carotid artery branches after flow diversion treatment. A meta-analysis. J Neuroradiol. 2019:46:9-14.

12. Ouared R, Larrabide I, Brina O, Bouillot P, Erceg G, Yilmaz H, Lovblad $\mathrm{KO}$, Mendes Pereira V. Computational fluid dynamics analysis of flow reduction induced by flow-diverting stents in intracranial aneurysms: a patient-unspecific hemodynamics change perspective. J Neurointerv Surg. 2016;8:1288-93.

13. Cebral JR, Mut F, Weir J, Putman C. Quantitative characterization of the hemodynamic environment in ruptured and unruptured brain aneurysms. AJNR Am J Neuroradiol. 2011;32:145-51.

14. Luo B, Yang X, Wang S, Li H, Chen J, Yu H, Zhang Y, Zhang Y, Mu S, Liu $Z$, Ding $G$. High shear stress and flow velocity in partially occluded aneurysms prone to recanalization. Stroke. 2011:42:745-53.

15. Fan J, Wang Y, Liu J, Jing L, Wang C, Li C, Yang X, Zhang Y. Morphological-hemodynamic characteristics of intracranial bifurcation mirror aneurysms. World Neurosurg. 2015;84(114-120):e112.

16. Stuhne GR, Steinman DA. Finite-element modeling of the hemodynamics of stented aneurysms. J Biomech Eng. 2004;126:382-7.

17. Malek AM, Alper SL, Izumo S. Hemodynamic shear stress and its role in atherosclerosis. JAMA. 1999:282:2035-42.

18. Cebral JR, Mut F, Raschi M, Scrivano E, Ceratto R, Lylyk P, Putman CM. Aneurysm rupture following treatment with flow-diverting stents: computational hemodynamics analysis of treatment. AJNR Am J Neuroradiol. 2011;32:27-33.

19. Hu P, Qian Y, Zhang Y, Zhang HQ, Li Y, Chong W, Ling F. Blood flow reduction of covered small side branches after flow diverter treatment: a computational fluid hemodynamic quantitative analysis. J Biomech. 2015:48:895-8 
20. Wang J, Ding Y, Wang Q, Wang Y, Mu S, Bi L, Li Y. The effect of placing flow-diverting stents in intracranial collateral arteries of miniature pig. Med Sci Monit. 2017;23:1428-35.

21. Dai D, Ding YH, Kadirvel R, Rad AE, Lewis DA, Kallmes DF. Patency of branches after coverage with multiple telescoping flow-diverter devices: an in vivo study in rabbits. AJNR Am J Neuroradiol. 2012;33:171-4.

22. Kulcsar Z, Ernemann U, Wetzel SG, Bock A, Goericke S, Panagiotopoulos V, Forsting M, Ruefenacht DA, Wanke I. High-profile flow diverter (silk) implantation in the basilar artery: efficacy in the treatment of aneurysms and the role of the perforators. Stroke. 2010;41:1690-6.

\section{Publisher's Note}

Springer Nature remains neutral with regard to jurisdictional claims in published maps and institutional affiliations.
Ready to submit your research? Choose BMC and benefit from:

- fast, convenient online submission

- thorough peer review by experienced researchers in your field

- rapid publication on acceptance

- support for research data, including large and complex data types

- gold Open Access which fosters wider collaboration and increased citations

- maximum visibility for your research: over $100 \mathrm{M}$ website views per year

At BMC, research is always in progress.

Learn more biomedcentral.com/submissions 